\title{
Alguns Planos Existentes em Portugal nas Áreas Social e de Crescimento e Emprego
}

Por Alda Teixeira Gonçalves

\section{Nota Prévia}

O objectivo do presente dossier foi o de sistematizar informação sobre alguns dos Planos, de âmbito nacional, existentes em Portugal, na área social e na do Crescimento e Emprego, para se obter uma panorâmica das orientações governamentais existentes nestas áreas. Apesar de uma preocupação de abranger e referenciar o maior número de Planos existentes, esta sistematização não é exaustiva.

Para cada um dos Planos efectua-se uma breve síntese das prioridades ou dos objectivos fundamentais em torno dos quais os Planos foram construídos e se devem operacionalizar. No caso dos Planos que se encontram acessíveis para consulta e download, aparece indicado o res- pectivo quer o Ministério responsável, quer o respectivo site, relevante para quem necessitar de obter maior informação e/ou aprofundar o conhecimento sobre estas matérias.

Refira-se ainda que boa parte dos documentos e Planos recenseados se enquadram em Estratégias Europeias, tratando-se portanto de documentos referenciais ao nível nacional e que respondem às especificidades problemáticas $\mathrm{e}$ territoriais portuguesas, mas que não deixam de se enquadrar em orientações europeias comuns aos 25 Estados-Membros da UE.

Estas orientações comuns europeias são em geral balizadas e articuladas com a Estratégia de Lisboa revista e com o Método Aberto de Coordenação que se encontra na base da sua operacionalização e implementação.

\section{Desenvolvimento Sustentável}

\section{Estratégia Nacional de Desenvolvimento Sustentável 2005-2015}

A Estratégia Nacional de Desenvolvimento Sustentável (ENDS) para 2005-2015, constituiu o pano de fundo dos Planos que vêm sendo apresentados.

Esta Estratégia propõe uma perspectiva de cidadania alargada e aprofundada em termos de concretização dos vectores chaves da Estratégia de Lisboa revista (o crescimento e o emprego), assente em prioridades europeias no âmbito do desenvolvimento sustentável, definidas no Con- selho Europeu de Gotemburgo, e nas prioridades definidas por Portugal para a sua concretização.

Assim, o "desígnio integrador e mobilizador para a aplicação da ENDS é o de: "Retomar uma trajectória de crescimento sustentado que torne Portugal, no horizonte de 2015, num dos países mais competitivos e atractivos da União Europeia, num quadro de elevado nível de desenvolvimento económico, social e ambiental e de responsabilidade social" .

${ }^{1}$ Cf. http://www.desenvolvimentosustentavel.pt 
A definição desta estratégia nacional de desenvolvimento sustentável e a sua implementação exigem mecanismos que assegurem a sua integração e coerência nas políticas de governo, assim como a articulação com a estratégia de desenvolvimento sustentável comunitária.

Esta Estratégia encontra-se organizada em torno dos seguintes objectivos:

- Preparar Portugal para a "Sociedade do Conhecimento"

- Crescimento Sustentado e Competitividade à Escala Global

- Melhor Ambiente e Valorização do Património Natural
- Mais Equidade, Igualdade de Oportunidades e Coesão Social

- Melhor Conectividade Internacional do País e Valorização Equilibrada do Território

- Papel Activo de Portugal na Construção Europeia e na Cooperação Internacional

- Uma Administração Pública mais Eficiente e Modernizada

No âmbito desta Estratégia foi também elaborado um Plano de Implementação (denominado PIENDS) para garantir a sua operacionalização e cuja monitorização se encontra prevista através de indicadores e metas para cada um dos objectivos antes enunciados.

(Aprovada na generalidade, em 2005-06-28, em Conselho de Ministros e esteve em Discussão Pública até 2006-10-15)

Coordenador Nacional da Estratégia de Lisboa e do Plano Tecnológico: Prof. Carlos Zorrinho
PRESIDÊNCIA DO CONSELHO DE MINISTROS
http://www.desenvolvimentosustentavel.pt
http://www.portugal.gov.pt

\section{Crescimento e Emprego}

\section{Programa Nacional de Acção para o Crescimento e o Emprego 2005-2008}

De acordo com o documento que pode ser consultado no Portal do Governo, "o Programa Nacional de Acção para o Crescimento e o Emprego 2005-2008 é um programa integrado e pragmático que Portugal vai desenvolver no contexto da União Europeia, face aos desafios colocados pela economia e pela sociedade globalizada em que tem que competir e se quer afirmar".

Responde às linhas orientadoras aprovadas por Conselho Europeu em três áreas fundamentais - macroeconómica, microeconómica e de emprego, respondendo também às recomendações em matéria de políticas económica e de emprego para Portugal efectuadas pela Comissão Europeia (CE) e às prioridades identificadas também pela $\mathrm{CE}$ no "Quadro da elaboração do Plano Nacional de Reformas, designadamente a sustentabilidade das contas públicas e do deficit externo, a investigação e desenvolvimento e a inovação, a concorrência nos serviços, o emprego, a organização do mercado de trabalho, a educação e a formação ao longo da vida".

Enquadra o Programa de Estabilidade e Crescimento, na dimensão Macroeconómica, o Plano Tecnológico na dimensão de competitividade e qualificação e o Plano Nacional de Emprego na dimensão do emprego.

Integra-se na Estratégia de Lisboa.

(Apresentado em 2005-10-28)

Coordenador Nacional da Estratégia de Lisboa e do Plano Tecnológico: Prof. Carlos Zorrinho PRESIDÊNCIA DO CONSELHO DE MINISTROS

http://www.cnel.gov.pt

http://www.portugal.gov.pt 


\section{Plano Tecnológico 2005-2008}

Este Plano propõe uma Estratégia de Crescimento com base no Conhecimento, na Tecnologia e na Inovação. Trata-se de um Plano de acção para o aumento sustentado da produtividade a médio e longo prazo. É entendido como um mapa de acções destinadas a criar melhores condições para a inovação e o foco central do sistema de inovação é a empresa.

Este Plano "constitui um dos pilares da implementação da Estratégia de Lisboa em Portugal, no qual estão agrupados os seus desafios mais emblemáticos: a aposta na sociedade do conhecimento, o aumento dos níveis de competência, o desenvolvimento científico e tecnológico e o estabelecimento dum processo de aprendizagem ao longo da vida"2.

O Plano Tecnológico estrutura-se em torno de 3 eixos de acção:

I. «Conhecimento - Qualificar os Portugueses para a sociedade do conhecimento»

II. «Tecnologia - Vencer o atraso científico e tecnológico»

III. «Inovação - Imprimir um novo impulso à inovação».

(Apresentado em 2005-10-24/Resolução do Conselho de Ministros n.ำ 190/2005)

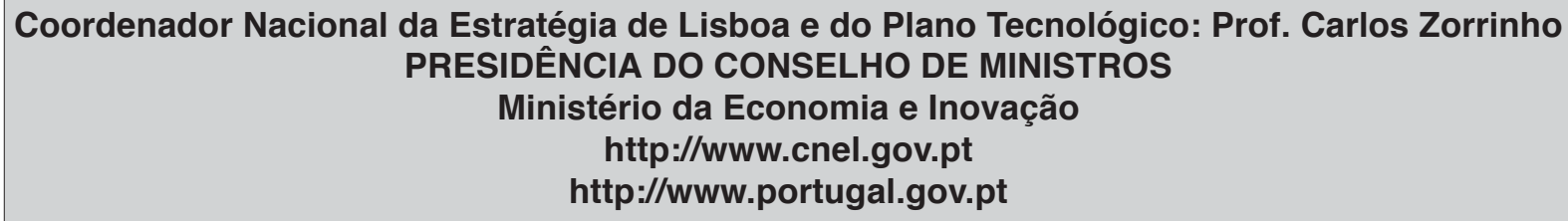

\section{Plano Nacional de Emprego 2005-2008}

De acordo com orientações europeias, o Plano Nacional de Emprego centra-se na promoção de um sistema de emprego capaz de alcançar o pleno emprego, preocupando-se simultaneamente em alcançar maior produtividade e maior coesão social e territorial. O sucesso deste sistema de emprego depende da sua capacidade para assegurar uma trajectória de crescimento sustentado, assente no conhecimento, na inovação e na qualificação dos recursos humanos, favorecedora de maior competitividade.

Neste âmbito, importa enfrentar os ambiciosos desafios para o emprego definidos na Estratégia de Lisboa e transpostos para a Estratégia Europeia para o Emprego (EEE), num contexto de globalização que se encontra "(...) associado ao alargamento da UE e ao reforço considerável de países como a China nos fluxos de comércio inter- nacional e na captação de Investimento Directo Estrangeiro (IDE), a par da rápida evolução tecnológica e do envelhecimento demográfico, impõe a Portugal a implementação de uma estratégia global de médio e longo prazo, fortemente articulada"4.

Os principais desafios estratégicos e grandes prioridades assumidas no PNE 2005-08 são as seguintes ${ }^{5}$ :

- Promover a criação de emprego, prevenir e combater o desemprego;

- Antecipar e gerir positivamente as reestruturações;

- Promover a flexibilidade com segurança no emprego;

- Reforçar a educação e qualificação da população;

- Modernizar o sistema de protecção social.

\footnotetext{
2 Consultável em http://www.cnel.gov.pt

3 Consultável em http://www.dgeep.mtss.gov.pt

${ }^{4}$ Cf. Site referido na nota anterior.

${ }^{5}$ Cf. http://www.portugal.gov.pt
} 
(Apresentado em 2005-09-23)

\section{Coordenadora: Dr. ${ }^{\text {a }}$ Cândida Soares \\ Direcção Geral de Estudos, Estatística e Planeamento \\ Ministério do Trabalho e da Solidariedade Social \\ http://www.dgeep.mtss.gov.pt \\ http://www.portugal.gov.pt}

\section{Social e Saúde}

\section{Relatório de Estratégia Nacional para a Protecção Social e Inclusão Social 2006-2008}

De acordo com as orientações europeias, a Estratégia Nacional para a Protecção Social e a Inclusão Social procurou responder de forma integrada aos desafios de cada uma das três áreas do MAC (Inclusão Social, Protecção Social e Saúde e Cuidados Continuados), identificando os principais eixos e prioridades de intervenção e as políticas e/ou instrumentos em curso e a implementar. A par desta abordagem estratégica global, o relatório procura assegurar o respeito pelas especificidades de cada área, de acordo com os seus próprios desafios e prioridades.

Este processo não se limitou às três vertentes do MAC foi alargado ao Programa Nacional de Reforma (Programa Nacional de Acção para o Crescimento e o Emprego 2005-08 - PNACE na designação portuguesa), com o objectivo de reforçar o papel da coesão social na Estratégia de Lisboa revista e a interacção entre os objectivos de crescimento e emprego com os da coesão social e vice-versa.

Neste contexto, o REN assenta em quatro eixos estratégicos fundamentais ${ }^{6}$ :

1. "Promover a modernização do sistema de protecção social, tornando-o um sistema mais forte e mais coerente, capaz de assegurar em simultâneo o reforço da protecção social de cidadania e a sustentabilidade do sistema numa tripla dimensão - social, económica e financeira.

2. "Promover de forma coerente, integrada e participada a expansão e qualificação da rede de serviços e equipamentos sociais em termos de número de respostas, qualidade das mesmas e equidade na distribuição territorial

3. "Assegurar a educação e formação ao longo da vida combatendo o abandono escolar precoce, facilitando a transição qualificada dos jovens para a vida activa e generalizando a utilização dos meios existentes para a qualificação dos recursos humanos entre a população activa

4. "Desenvolver modelos de intervenção mais focalizados e territorializados de combate à pobreza."

Este documento integra o Plano Nacional de Acção para a Inclusão, o Relatório Nacional de Estratégia para as Pensões e o Plano Nacional para os Cuidados de Saúde e Cuidados de Longa Duração, para o período 2006-2008.

Integra-se na Estratégia Europeia de Protecção Social e Inclusão Social.

Estrutura de Coordenação: Comité de Redacção
Apoio Técnico: Instituto de Segurança Social / Direcção-Geral de Estudos,
Estatística e Prospectiva
Ministério do Trabalho e da Solidariedade Social
(Não publicado.)

${ }^{6}$ Cf. Relatório de Estratégia Nacional para a Proteç̧ão Social e Inclusão Social 2006-2008 - Parte 2, MTSS/ISS, pp. 5, 6 (Documento policopiado), Setembro de 2006. 


\section{Plano Nacional de Acção para a Inclusão 2006-2008}

O Plano Nacional de Acção para a Inclusão (PNAI), para o período de 2006-2008, é um documento multi-sectorial e multi-dimensional, de coordenação estratégica e operacional das políticas de combate à pobreza e à exclusão social, em observância da Estratégia de Lisboa e fundado em objectivos comuns aplicados a todos os Estados-Membros da União Europeia.

O PNAI visa, deste modo, a adopção de medidas que permitam combater a pobreza persistente e encontra-se estruturado em torno de 3 prioridades:

i) Combater a pobreza das crianças e dos idosos, através de medidas que assegurem os seus direitos básicos de cidadania;

ii) Corrigir as desvantagens na educação e formação/qualificação;

iii) Ultrapassar as discriminações, reforçando a integração das pessoas com deficiência e dos imigrantes.

(Aprovado em Conselho de Ministros de 2006-11-07)

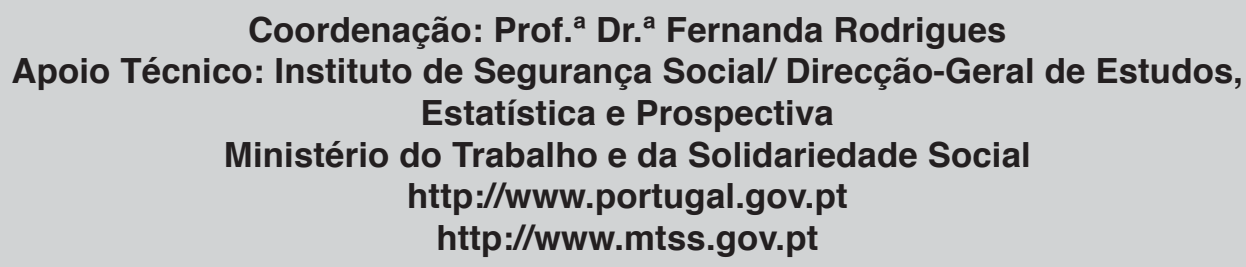

\section{Relatório Nacional de Estratégia para as Pensões 2006-2008}

Este relatório centra-se fundamentalmente, na "proposta de reforma do regime geral da segurança social (...) apresentada pelo Governo que assenta na necessidade de reforçar a protecção social em convergência com a União Europeia, e em simultâneo dar resposta ao inevitável processo de envelhecimento populacional e suas consequências em toda a sociedade.

"O novo quadro de referência da estratégia de modernização do sistema de Protecção Social apresentado pelo Governo assentará cada vez mais num sistema de três patamares:

a) Um primeiro patamar de protecção básica de cidadania, constituído por prestações de combate à pobreza, sujeitas a condições de recur- sos e financiadas pela solidariedade nacional por recurso aos impostos;

b) Um segundo patamar baseado nos princípios da solidariedade profissional e inter-geracional, incorporando elementos de natureza redistributiva, estruturado através de um regime contributivo, funcionando em regime de repartição e financiado através das contribuições e cotizações das entidades empregadoras e dos trabalhadores;

c) Um terceiro patamar relativo às poupanças complementares de cada cidadão, funcionando numa base opcional e com o objectivo de melhorar a protecção na velhice garantida pelo sistema público."

\section{Estrutura de Coordenação: Comité de Redacção \\ Apoio Técnico: Instituto de Segurança Social/ Direcção-Geral de Estudos, Estatística e Prospectiva \\ Ministério do Trabalho e da Solidariedade Social (Não publicado.)}

Cf. Relatório de Estratégia Nacional para a Protecção Social e Inclusão Social 2006-2008 - Parte 3, MTSS/ISS, pp. 2 (Documento policopiado), Setembro de 2006 


\section{Plano Nacional para os Cuidados de Saúde e Cuidados de Longa Duração, para o período 2006-2008}

No site da Direcção-Geral da Saúde surge a referência ao Plano Nacional de Saúde 2004-2010, que contém orientações estratégicas para o pacote mínimo de actividades que as instituições ligadas ao Ministério da Saúde devem assegurar no contexto de uma agenda para ganhos em saúde e em eficiência. Para além de um guia de acção, define as orientações estratégicas, prioridades e metas a alcançar.

É em consonância com este Plano mais abrangente e já em vigor desde 2004, que se desenvolve a estratégia patente no Plano Nacional para os Cuidados de Saúde e Cuidados de Longa Duração, para o período 2006-2008.
Neste âmbito, pode dizer-se que "o novo modelo permite o desenvolvimento de novos serviços, ou linhas de cuidados, que visam oferecer respostas ajustadas às necessidades dos diferentes grupos de pessoas idosas e com problemas de dependência nos diferentes momentos e circunstâncias da própria evolução das doenças e eventuais complicações sociais que ocorram.

"Este sistema de cuidados de longa duração ou continuados promove, assim, a continuidade entre os cuidados de cariz comunitário e os cuidados de internamento hospitalar de doentes agudos e os de apoio social, complementando os níveis de cuidados primários e cuidados especializados hospitalares"

\section{Estrutura de Coordenação: Comité de Redacção}

Apoio Técnico: Instituto de Segurança Social / Direcção-Geral de Estudos, Estatística

e Prospectiva / Direcção-Geral da Saúde

Ministério do Trabalho e da Solidariedade Social

Ministério da Saúde

(Encontra-se disponível o Plano Nacional de Saúde 2004-2010, em http://www.dgs.pt)

\section{Plano Nacional Contra a Violência Doméstica 2003-2006}

O II Plano Nacional Contra a Violência Doméstica 2003-2006 possui como principal objecto de intervenção a violência doméstica exercida sobre as mulheres.

Cumpre à Comissão para a Igualdade e para os Direitos das Mulheres (CIDM) a dinamização, o acompanhamento e a execução de todas as medidas constantes do Plano.
Este Plano organiza-se em torno dos seguintes eixos:

- Informação, Sensibilização e Prevenção;

- Formação;

- Legislação e sua Aplicação;

- Protecção da Vítima e Integração Social;

- Investigação;

- Mulheres Imigrantes.

(Aprovado em 2003-06-13 / Resolução de Conselho de Ministros n. ${ }^{\circ}$ 88/2003)

Coordenadora: Dr. ${ }^{a}$ Elza Pais

Comissão para a Igualdade e para os Direitos das Mulheres (CIDM) PRESIDÊNCIA DO CONSELHO DE MINISTROS http://cidm.madbug.com

\footnotetext{
${ }^{8}$ Consultável em http://www.dgs.pt

${ }^{9}$ Cf. Relatório de Estratégia Nacional para a Protecção Social e Inclusão Social 2006-2008 - Parte 4, MTSS/ISS, p. 8 (Documento policopiado), Setembro de 2006.00
} 


\section{Plano Nacional Para a Igualdade 2003-2006}

De acordo com as orientações patentes na Plataforma de Acção de Pequim e sua actualização, foram assumidas as áreas prioritárias de intervenção no âmbito da igualdade entre géneros, o trabalho e o emprego, a conciliação da vida profissional e familiar, o combate à violência (objecto de um Plano específico antes referido), o poder e tomada de decisão e a educação/sensibilização.

Neste contexto, o II Plano Nacional para a Igualdade 2003-2006, possui uma dupla abordagem, em termos de intervenção:

- Medidas consideradas estruturantes a implementar pela Administração Pública no sentido de comprometerem e abrangerem todos os Ministérios. O Plano propõe a criação equipas represen- tativas das diferentes unidades orgânicas, em cada Ministério, responsáveis pela disseminação da temática da igualdade, a médio e longo prazo, assegurando a implementação do Plano.

- Medidas por grandes áreas de intervenção que exigem uma estreita colaboração com todos os agentes sociais cidadãos/ãs, empresas, organizações não governamentais, outras associações e organizações da sociedade civil, parceiros sociais, etc. As áreas de intervenção consideradas são as seguintes:

- Actividade Profissional e Vida Familiar;

- Educação, Formação e Informação;

- Cidadania e Inclusão Social;

- Cooperação com os países da CPLP.

(Resolução de Conselho de Ministros n. ${ }^{\circ}$ 184/2003)

Coordenadora: Dr. ${ }^{a}$ Elza Pais

Comissão para a Igualdade e para os Direitos das Mulheres (CIDM) PRESIDÊNCIA DO CONSELHO DE MINISTROS http://cidm.madbug.com

\section{Plano Nacional Contra a Droga e as Toxicodependências 2005-2012}

O Plano Nacional Contra a Droga e as Toxicodependências 2005-2012 foi elaborado na continuidade da Estratégia Nacional de Luta contra a Droga (publicada em Maio de 1999), adaptando-a à realidade actual e considerando vários documentos nacionais, nomeadamente o Programa do XVII Governo Constitucional, as Grandes Opções do Plano para 2005-2009, o Orçamento de Estado para 2005, o Plano Nacional de Saúde 2004-2010 e a "Carta de Missão" apresentada pelo Coordenador Nacional do Combate à Droga e à Toxicodependência ao Senhor Ministro da Saúde.

Em consonância com a opção Europeia, Portugal propôs um Plano (Estratégico) Nacional para 2005-2012, complementado por um Plano de Acção até 2008 (a aprovar no início de 2006), que prevê uma avaliação de impacto seguida de um novo Plano de Acção para 2009-2012.
O Plano estrutura-se em torno de seis eixos subdivididos em vectores, para os quais são definidos objectivos gerais e prioridades.

- Eixos contemplando Áreas Transversais:

1. Coordenação

2. Cooperação internacional

3. Informação, investigação e formação e avaliação

4. Reordenamento jurídico

- Eixos relativos a Áreas de Missão:

5. Redução da procura

Prevenção

Dissuasão

Redução de Riscos e Minimização de

Danos

Tratamento

Reinserção

6. Redução da oferta 
Este Plano propõe uma abordagem integrada do fenómeno dos consumos e das toxicodependências a diferentes níveis de intervenção, local, regional e nacional.
O seu objectivo final é conseguir promover, de forma significativa, a redução do consumo de drogas entre a população e diminuir os seus efeitos negativos em termos sociais e de saúde.

(Aprovado em Conselho de Ministros, em 2006-08-24)

\section{Entidade Coordenadora: Instituto das Drogas e Toxicodependências (IDT) Ministério da Saúde http://www.idt.pt http://www.portalsaude.pt}

\section{Plano de Acção para a Integração das Pessoas com Deficiência ou Incapacidade - PAIPDI 2006-2009}

O I Plano de Acção para a Integração das Pessoas com Deficiência ou Incapacidade 2006-2009 apresenta um conjunto de medidas e acções com o objectivo de promover a reabilitação, a integração e a participação das pessoas com deficiência na sociedade.

Um dos objectivos deste Plano é o de fomentar e sensibilizar a sociedade em geral para as questões da deficiência, combatendo os preconceitos e as atitudes discriminatórias.

O PAIPDI encontra-se organizado em torno de eixos estratégicos, que apontam para três grandes áreas de intervenção:
- Eixo 1 - Acessibilidades e Informação;

- Eixo 2 - Educação, Qualificação e Emprego;

- Eixo 3 - Habilitação e Condições de Vida Dignas.

Assim, a implementação das medidas inscritas neste Plano deverá contribuir para o desenvolvimento efectivo de uma sociedade mais coesa que integra os cidadãos com deficiência e para um aumento significativo da qualidade de vida destes cidadãos e suas famílias.

(Aprovado em 2006-09-21 / Resolução de Conselho de Ministros n. ${ }^{\circ}$ 120/2006)

Entidade Coordenadora: Secretariado Nacional para a Reabilitação e Integração das Pessoas com Deficiência (SNRIPD) Secretaria de Estado da Reabilitação (promotora) Ministério do Trabalho e da Solidariedade Social http://www.mtss.gov.pt/acessibilidade/tpl_intro_destaque.asp?688 


\section{Ordenamento do Território}

\section{PNPOT - Programa Nacional da Política de Ordenamento do Território (2005)}

Este Programa possui como objectivo fundamental a concretização da estratégia de ordenamento, de desenvolvimento e de coesão territorial do País.

As opções estratégicas consignadas no documento do Programa partem de um enquadramento do país nos contextos ibérico, europeu e mundial, da caracterização das condicionantes, dos problemas, das principais tendências e cenários de desenvolvimento territorial, assim como do diagnóstico estratégico das diversas regiões.

As respostas políticas a este enquadramento corporizam-se em objectivos estratégicos, objectivos específicos e medidas que expressam as principais linhas de intervenção a desenvolver no âmbito do ordenamento do território para o horizonte de 2025.

O PNPOT especifica também a forma como os diversos instrumentos de planeamento e de gestão do território deverão contribuir para concretizar a estratégia e o programa de acção estabelecidos, assim como a relação com os outros Instrumentos de gestão territorial, consagrando orientações específicas para cada um dos tipos de Planos de ordenamento do território (como sejam os Planos Sectoriais, os Planos Especiais, os
Planos Regionais, os Planos Intermunicipais e os Planos Municipais).

Por último refiram-se os principais objectivos estratégicos do PNPOT:

" $1 .{ }^{\circ}$ Conservar e valorizar a biodiversidade e o património natural, paisagístico e cultural, utilizar de modo sustentável os recursos energéticos e geológicos, e prevenir e minimizar os riscos.

$2 .^{\circ}$ Reforçar a competitividade territorial de Portugal e a sua integração nos espaços ibérico, europeu e global.

3. ${ }^{\circ}$ Promover o desenvolvimento policêntrico dos territórios e reforçar as infra-estruturas de suporte à integração e à coesão territoriais.

$4 .^{\circ}$ Assegurar a equidade territorial no provimento de infra-estruturas e de equipamentos colectivos e a universalidade no acesso aos serviços de interesse geral, promovendo a coesão social.

5. ${ }^{\circ}$ Expandir as redes e infra-estruturas avançadas de informação e comunicação e incentivar a sua crescente utilização pelos cidadãos, empresas e administração pública.

6. ${ }^{\circ}$ Reforçar a qualidade e a eficiência da gestão territorial, promovendo a participação informada, activa e responsável dos cidadãos e das instituições." 10

(Aprovado em Conselho de Ministros em 2006-03-16 para efeitos de discussão pública)

Entidade Coordenadora: DGOTDU (Direcção Geral do Ordenamento do Território e Desenvolvimento Urbano)

Ministério do Ambiente, do Ordenamento do Território e do Desenvolvimento Regional http://www.territorioportugal.pt/Proposta.aspx

${ }^{10}$ Cf. Doc. PNPOT, p. 12, no site http://www.territorioportugal.pt/Proposta.aspx 


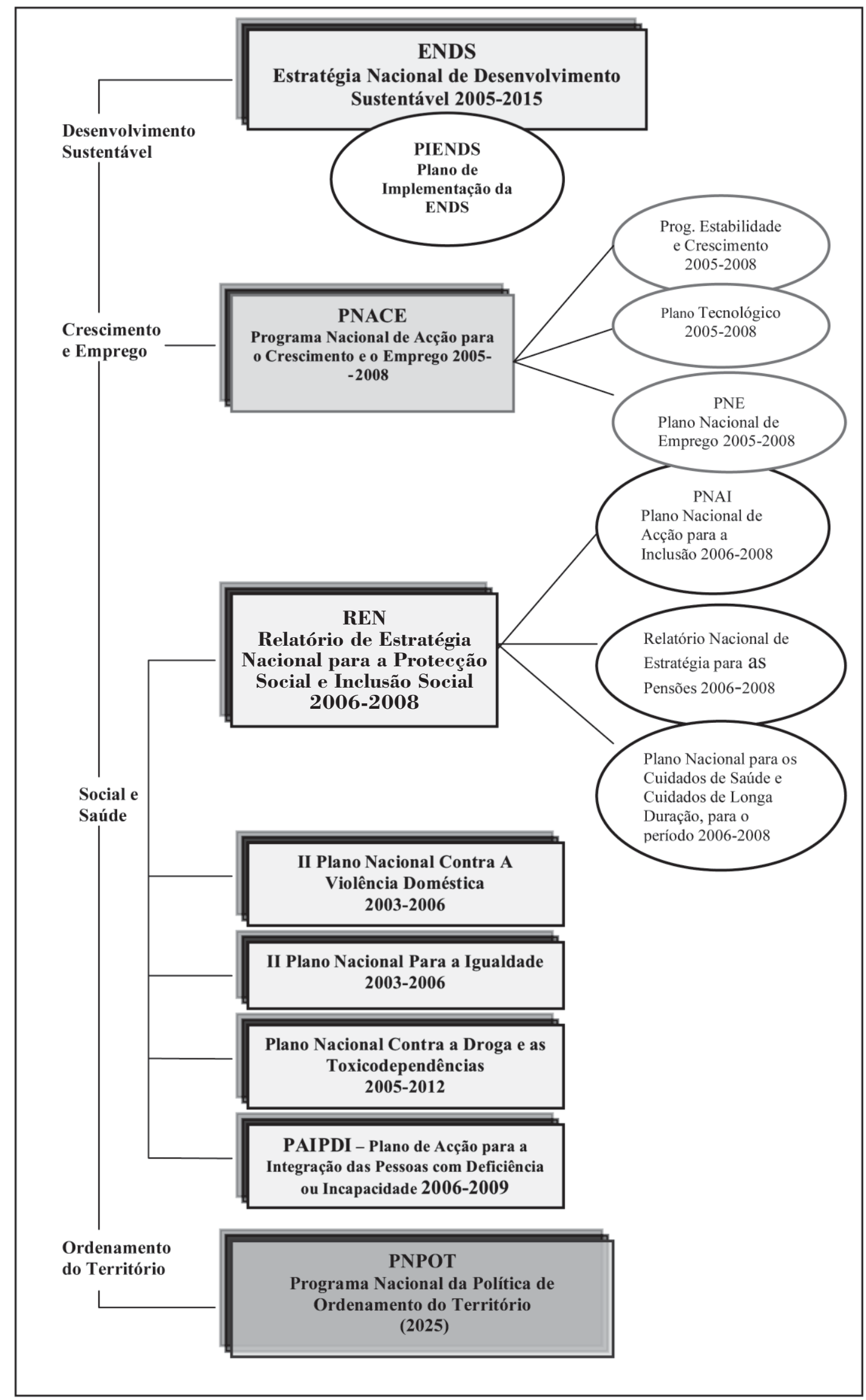

